\title{
Educational Context: Preparing Accounting Students To Identify Ethical Dilemmas
}

Mary Jo Billiot, New Mexico State University, USA

David Daniel, New Mexico State University, USA

Sid Glandon, University of Texas at El Paso, USA

TerryAnn Glandon, University of Texas at El Paso, USA

\begin{abstract}
We examine the effect of different contexts in an educational process on measures of ethical sensitivity and levels of moral reasoning of accounting majors in the first Intermediate Accounting course. The educational process compared a context that centers on ethical issues with one that focuses on technical accounting issues. At the end of the semester, we measured students' ethical sensitivity and levels of moral reasoning in an environment that does not provide obvious ethical implications. Results from a sample of 193 undergraduate students indicate that those exposed to the ethical context demonstrated higher levels of ethical sensitivity and moral reasoning than students exposed to the technical accounting context. In contrast to prior studies in which participants were asked to respond to an obvious ethical issue, our research instrument contains only subtle clues about a developing ethical dilemma.
\end{abstract}

Keywords: Accounting Ethics Education; Ethical Dilemmas; Ethical Sensitivity; Moral Reasoning

\section{INTRODUCTION}

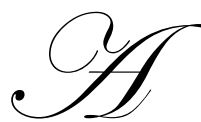

ccountants must constantly be sensitive to potential competing interests of various stakeholders when evaluating decisions made by managers or clients. Development of this sensitivity is important because ethical conflicts can occur "when accountants perceive that their duties toward one group are inconsistent with their duties and responsibilities toward some other group or their own self-interests" (Mintz 2007, 34). Shaub, Finn and Munter (1993) suggest that ethics education could improve ethical sensitivity by focusing on recognition skills. A central theme of accounting ethics education involves coaching students to look for unethical behavior, such as solving ethics cases and writing two-minute papers based on contemporary issues from the business press. The implicit outcome is that providing exposures to educational interventions that include relatively obvious cues will develop recognition skills and increase levels of ethical sensitivity. Our goal in this paper is to further the discussion by examining whether the context of an educational process has an effect on ethical sensitivity in a setting that does not provide obvious ethical implications.

As students learn theory and application of accounting concepts, there is an opportunity to begin evaluating the ethical implications of decisions when recording transactions and preparing financial reports. In this research, we utilized an educational process that incorporated active learning, a structured decision-making model, and corrective feedback in varied accounting situations to prepare students early in their academic careers to become sensitive to ethical issues that accountants face in practice. The educational process was administered in two settings - the first focused on accounting transactions and internal controls (accounting context) and the second emphasized the ethical responsibilities of the accountant (ethical context). At the end of the semester, the participants completed a webbased survey that consisted of a multi-phase, simulated real-life accounting scenario, which measured ethical sensitivity in a setting in which the existence of an ethical issue was not obvious.

A second aspect of this research was to examine the effect on moral reasoning when the educational process is delivered in an ethical context versus an accounting context. Moral development literature supports the notion that higher education, in general, contributes to the ethical development of students (Rest, 1979, 1986, 1994; 
and others). In accounting ethics research, results demonstrate that educational interventions have a positive impact on moral reasoning (c.f., Massey and Thorne, 2006, and Green and Weber, 1997). We extend this line of research by varying the context in which the educational process is delivered.

The results of the current study indicate that an educational process framed in an ethical context may help students become more attuned to the potential existence of an ethical dilemma and enhance their ethical sensitivity. The effect of this educational process on levels of moral reasoning is more ambiguous, which will be addressed in the discussion section. The educational and measurement processes that we used may provide a basis for advancing the ethics education dialogue.

\section{LITERATURE REVIEW}

Ethical sensitivity in accounting has been modeled and measured over the last two decades (c.f., Shaub et al., 1993; Wright et al., 1998; Cohen et al., 2001; Patterson, 2001; and Coyne et al., 2005), often using Rest's (1979, 1994) four-stage Model of Ethical Action. More attention has been given to the last three stages (ethical judgment, ethical intention, and ethical behavior), with less focus on the first stage - ethical issue recognition. However, it can be argued that ethical issue recognition-or ethical sensitivity-should be studied more thoroughly because "[b]efore one can act ethically, one must understand that an ethical issue exists" (Armstrong et al., 2003, 4). Prior research indicates that higher education alone is not sufficient for the development of ethical sensitivity. Cohen, et al. (2001) compared the ethical sensitivity of sophomores to seniors in a business school with no specific ethics curriculum and found no change in the levels of ethical sensitivity, even though the seniors had acquired two additional years of higher education.

There is limited research on the impact of educational processes specifically designed to increase ethical sensitivity for accounting majors. Early research indicates that exposure to the AICPA Code of Professional Conduct helps accounting students become sensitive to ethical issues (Fulmer and Cargile, 1987). More recently, Coyne et al. (2005) compared ethics instruction in an active learning environment to ethics instruction using a traditional lecture method and found that active learning was more effective at improving ethical sensitivity.

Rest (1986) suggests that ethics education contributes to moral development in undergraduate, graduate, and professional school students (as cited in Douglas and Schwartz, 1998). Huss and Patterson (1993) propose that the moral development of accounting students "...can be enhanced through the educational process" (235). Other accounting research also supports the notion that accounting ethics education affects levels of moral reasoning. For example, a cognitive feedback process, developed by Massey and Thorne (2006), was applied to audit dilemmas and found to improve ethical reasoning. In Abdolmohammadi's (2005) study, the level of moral reasoning increased significantly as a result of an educational intervention in a graduate capstone accounting course. Ethics education also was found to be effective at increasing the moral reasoning ability of junior and senior accounting students in a study conducted by Delaney and Coe (2008).

Some researchers have distinguished moral reasoning within an accounting framework from general moral reasoning. In a study conducted by Earley and Kelly (2004), auditing students were exposed to multiple educational interventions and two different instruments were used to measure moral reasoning. The results indicate that the educational interventions were effective at improving students' accounting-context moral reasoning when measured by Thorne's (2000) Accounting Ethical Dilemma Instrument (AEDI). In contrast, there was no increase in the DIT scores which measure general moral reasoning. Welton, LaGrone and Davis (1994) developed an instrument to measure ethical reasoning of students receiving ethics instruction within an accounting framework. Their results report an improved level of moral reasoning for graduate students enrolled in an accounting ethics course.

Some researchers incorporated the AICPA Professional Code of Conduct as a foundation in which to teach ethics education. For example, Green and Weber (1997) observed that students who completed an auditing course that emphasized the Code reasoned at higher levels than students who had not taken the course. In a study conducted by Fleming, Romanus, and Lightner (2009) in which students were exposed to an audit context or a corporate accounting context, those that participated in the audit condition exhibited significantly greater levels of moral reasoning. 


\section{RESEARCH QUESTIONS}

Research in ethics education is typically framed in the context of obvious ethical dilemmas (c.f, Fulmer and Cargile, 1987, and Coyne et al., 2005). Outside the classroom, however, there may be few direct indicators of unethical behavior. The challenge is to increase ethical sensitivity through educational processes to prepare students for the uncertainties of the business environment. Thus, our first research question addresses the level of ethical sensitivity that students exhibit when evaluating an ambiguous situation:

Research Question \#1: Will students who participate in an educational process framed in an ethical context demonstrate greater ethical sensitivity than students who participate in an educational process framed in an accounting context?

As described in the literature review, results from earlier research indicate a connection between ethics education and levels of moral reasoning. The context in which the educational process is framed is important. In a study conducted by Fleming et al. (2009), the ethical component of the educational process was grounded in an audit setting, which was compared to an educational process in a general accounting context. Similar to the studies listed above, the ethics content included in their auditing course may have led to a greater level of moral reasoning. Based on this discussion, we pose the following research question:

Research Question \#2: Will students who participate in an educational process framed in an ethical context exhibit a higher level of moral reasoning when making a professional accounting judgment compared to those who participate in an educational process framed in an accounting context?

\section{RESEARCH METHOD}

We investigated the impact of an educational process on the ethical sensitivity and moral reasoning of intermediate accounting students. The educational process described below was conducted over an academic semester. Near the end of the semester, students completed a web-based survey to measure their ethical sensitivity and level of moral reasoning. Upon completion of the survey, they printed a certificate which was submitted the day of the final exam to receive credit that represented 15 percent of the final exam score. ${ }^{1}$

Two groups participated in the educational processes. In one semester, all of the students participated in an educational process framed in the accounting context and in a subsequent semester, all of the students participated in an educational process framed in the ethical context.

\section{Educational Process}

We administered an educational process that incorporates active learning, a structured decision-making model, and corrective feedback. These are described first, followed by a discussion of the two different contexts in which each educational process was conducted. Each week for 12 weeks, the instructor began class by introducing and briefly discussing a new case (within the ethical context or the accounting context). Students spent approximately 15 minutes discussing the case among themselves and completed a decision-making model that was adapted from Langenderfer and Rockness (1989). The process concluded with a classroom discussion in which one or more students were asked to discuss their recommendations.

Decision-making model (adapted from Langenderfer and Rockness, 1989):

Step 1-Briefly list the basic facts.

Step 2-Identify the ethical issue and stakeholders affected.

Step 3-From the list of values provided, what are the two or three most important values?

Step 4-What are the realistic alternatives available to you?

\footnotetext{
${ }^{1}$ All students who participated in the survey received the maximum credit. There was no attempt to "grade" this portion of the exam.
} 
Step 5-In terms of the values you identified, evaluate the alternatives.

Step 6-What are the consequences of the alternatives that you have identified?

Step 7-What decision would you make?

\section{Accounting Context Group}

Cases were introduced as exercises in analyzing possible deficiencies in internal controls and inadequacies in the accounting system. The title of each case omitted any reference to ethics. Although the students were not discouraged from talking about ethical responsibility, the emphasis was on the proper structure of the transaction and/or accounting system to prevent errors or irregularities. The instructor used this as a forum to emphasize Steps $1,4,6$ and 7 of the decision-making model.

\section{Ethical Context Group}

This group participated in a similar process with the following modifications. At the beginning of the semester, the AICPA Code of Professional Conduct was introduced to establish a foundation on which to build an understanding of the ethical responsibilities of accountants. Utilizing the same case fact patterns as presented to the accounting context group, the instructor introduced and briefly discussed the case within an ethical context. The case was clearly labeled "Ethics Case" and the discussion focused on the ethical responsibilities of accountants (Steps 2, 3,5 , and 7). The students used the same decision-making model and were given the same amount of time to discuss and document their responses.

\section{Research Instrument}

The research instrument, which was administered at the end of the semester, consisted of a multi-phase scenario that disclosed progressively more information with each phase. During the development stage, the instrument was presented to a panel of academic experts for comments and the educational process was administered by the primary instructor and two other instructors (one at the same university and one at another university). After refinement, the instrument was pilot tested in undergraduate accounting classes; the results of the pre-tests are not included in the analysis or results.

The instructions directed participants to assume the role of a recent graduate, who was hired as an entrylevel internal auditor, so they would focus on examining processes and systems. Beginning with company background and job responsibilities, the scenario was presented in four phases which progressively added more information about a developing (unethical) situation, as well as extraneous information to help disguise that the scenario related to ethics. After Phase 4, the unethical nature of the situation was fully disclosed and the participants were asked to make a professional accounting judgment.

The scenario involves a management practice which results in year-end over-production of inventory in order to meet company performance criteria. The case background and Phase 1 of the scenario provide a broad overview of the company and the employee's (participant's) job. Phase 2 of the scenario provides the first indication of increased year-end production volume and the employee questions the controller about the increased production. ${ }^{2}$ In Phase 3, loaded containers awaiting shipment are mentioned, thus further indicating that excess production is taking place. In Phase 4, the employee learns that demand for the company product is steady throughout the year and that the controller misrepresented the changes in demand and the reason for increased production. Substantial additional information was included in the scenario to distract the participant from the ethical dimension of the case.

After each phase, the participants were asked to indicate their level of agreement with a series of statements. We used several statements from Cohen et al.'s (2001) instrument to capture the participants' perceptions of management. Cohen et al.'s dependent measure of overall ethical awareness, Management is ethical, was used to measure ethical sensitivity in our study. The remaining statements were simply distractors to disguise the ethical implications of the case. A seven-point Likert-type scale was used, with responses ranging from strongly

\footnotetext{
${ }^{2}$ The expert panel identified the ethical dimension at this point.
} 
disagree (1) through neutral (4) to strongly agree (7). The instrument also contained demographic questions to be used as control variables (gender, age, GPA, work experience, and ethics courses). The research instrument is available upon request.

After Phase 4, the ethical dimension of the scenario was revealed to the participant, along with a reminder about the existence of a company hotline to report ethical violations. The participants were asked if they would call the hotline and provide rationale to support their decision by selecting one of a series of statements adapted from Green and Weber (1997). These statements provide a measure of the levels of moral reasoning (Kohlberg, 1981 and 1984), which range from individualistic (level 1) to principled (level 5).

\section{METHOD}

Repeated measures ANOVA with between-subjects factors was used to test the equality of means. Repeated measures were required because the dependent variable was measured after each of the four phases of the scenario. We compared levels of ethical sensitivity for three groups - the accounting context group, the ethical context group, and a comparison group of students that did not participate in the educational process. For participants who elected to call the company hotline, a one-way ANOVA with three levels (groups as described above) was used to test the levels of moral reasoning.

\section{RESULTS}

The study was conducted with students enrolled in the first course of Intermediate Accounting at a large public AACSB-accredited university. All enrolled students participated, but the analysis and discussion is limited to accounting majors, resulting in 193 responses. The survey was administered in accordance with guidelines set forth by the US Office of Human Participant Protections. No identifying information was requested from the respondents. $^{3}$ As presented in Table 1, 60 percent (116) were female, the average age was 24.7 years, and the average self-reported GPA was 2.92/4.0. The educational process was administered over two semesters. In the first semester, 62 students participated in the accounting context and in the second semester, 76 students participated in the ethical context. In a subsequent semester, a comparison group $(\mathrm{n}=55)$ did not participate in the educational process but did complete the survey.

Table 1: Demographic Data

\begin{tabular}{|ccccc|}
\hline Gender: & Total & Accounting Context & Ethical Context & Comparison Group \\
\cline { 2 - 5 } Male & 77 & 30 & 33 & 23 \\
Female & 116 & 32 & 43 & 32 \\
\cline { 2 - 5 } & 193 & 62 & 76 & 55 \\
Average Age & 24.7 & 24.3 & 25.5 & 24.2 \\
Average GPA & 2.92 & 2.96 & 2.86 & 2.93 \\
\hline
\end{tabular}

Research Question \#1 addresses whether students who participated in an educational process framed in an ethical context demonstrate greater ethical sensitivity than students who participated in an educational process framed in an accounting context. As presented in Table 2, the results indicate that there are significant differences by group $(\mathrm{p}=0.011)$, by phase $(\mathrm{p}<0.001)$, and by gender $(\mathrm{p}=0.020)$. As the participants were exposed to each phase, the means decreased, indicating an increase in ethical sensitivity. The ethical context group $($ mean $=4.06)$ was significantly more sensitive than the accounting context group (mean $=4.46, \mathrm{p}=0.077$ ) and the comparison group (mean $=4.54, \mathrm{p}=0.004)$ over the four phases. There was no important difference between the accounting context and the comparison groups $(\mathrm{p}=0.511)$ and there was no group-phase interaction $(\mathrm{p}=0.379)$. As anticipated, these results provide support that the educational process within an ethical context leads to greater ethical sensitivity.

\footnotetext{
${ }^{3}$ Upon completion of the survey, students printed a certificate of completion and submitted it for credit. There was no connection between the survey response, the demographic information, and the certificate.
} 
With the exception of gender, none of the other control variables (age, GPA, work experience, and ethics courses) were important. Females were more ethically sensitive than males regardless of group affiliation $(\mathrm{p}=$ 0.020). This result is consistent with Cohen, Pant, and Sharp (2001) who found that women exhibited higher levels of ethical awareness than males.

Table 2: Means and Repeated Measures ANOVA Results for RQ1

\begin{tabular}{|c|c|c|c|c|c|c|}
\hline $\begin{array}{l}\text { Panel A } \\
\text { Group }\end{array}$ & $\mathbf{n}^{\mathrm{a}}$ & $\begin{array}{c}\text { Overall } \\
\text { Mean }\end{array}$ & $p=0.011$ & & & \\
\hline $\begin{array}{l}\text { Accounting Context } \\
\text { Ethical Context } \\
\text { Comparison Group }\end{array}$ & $\begin{array}{c}58 \\
62 \\
52 \\
172\end{array}$ & $\begin{array}{l}4.46 \\
4.06 \\
4.55\end{array}$ & & & & \\
\hline \multicolumn{7}{|l|}{ Panel B } \\
\hline Group & $\mathbf{n}$ & Phase 1 & Phase 2 & Phase 3 & Phase 4 & p \\
\hline Overall mean by Phase & 172 & 5.09 & 4.52 & 4.00 & 3.75 & $<0.001$ \\
\hline Ethical Context & 62 & 4.84 & 4.16 & 3.56 & 3.50 & 0.077 \\
\hline Accounting Context & 58 & 5.31 & 4.61 & 4.17 & 3.76 & \\
\hline Ethical Context & 62 & 4.84 & 4.16 & 3.56 & 3.50 & 0.004 \\
\hline Comparison Group & 52 & 5.11 & 4.79 & 4.28 & 4.00 & \\
\hline Accounting Context & 58 & 5.31 & 4.61 & 4.17 & 3.76 & 0.511 \\
\hline Comparison Group & 52 & 5.11 & 4.79 & 4.28 & 4.00 & \\
\hline $\begin{array}{l}\text { Group x Phase Interaction } \\
\text { Gender }\end{array}$ & & & & & & $\begin{array}{l}0.379 \\
0.020\end{array}$ \\
\hline
\end{tabular}

After Phase 4, the unethical nature of the situation was disclosed and the participants were asked whether they would call the company hotline. The participants justified their decision based on Kohlberg's $(1981,1984)$ levels of moral reasoning, which range from individualistic (level 1) to principled (level 5). Decision justification is addressed by the second research question, which states that students who have participated in an educational process within the ethical context are more likely to exhibit a higher level of moral reasoning compared to those who did not.

The analysis was limited to the 139 respondents ( 80.8 percent of the sample) who chose to call the hotline. As presented in Table 3, results indicate a significant difference between groups $(p=0.002)$. However, the difference was between the comparison group (mean $=3.86)$ and the accounting context group (mean $=2.90$ ). There was no difference between the ethical context group (mean $=3.41)$ and the other two groups. This result was unexpected and will be discussed in the following section. Of the control variables, only work experience had a significant association to higher levels of moral reasoning $(\mathrm{p}=0.008)$. Although Fleming et al. (2009) found a significant positive association between years of accounting experience and moral reasoning, our results indicate that general work experience may be the influencing factor that affects moral reasoning. 
Table 3: Means and ANOVA Results for RQ2

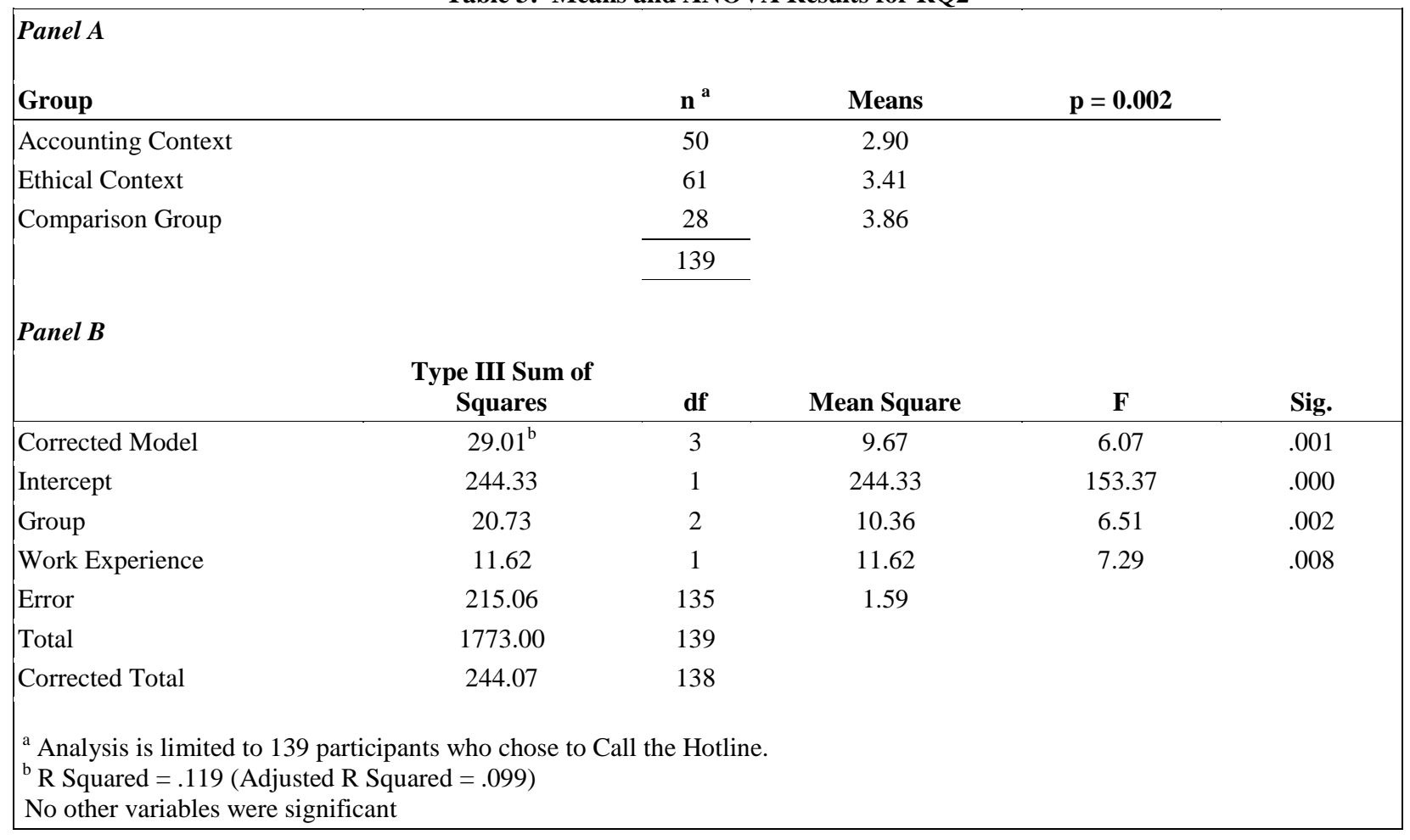

\section{Additional Analysis}

In our study, a pretest was inappropriate because of the risk of sensitizing the participants and possibly creating demand effects. As an alternative, we included a comparison group that represents intermediate accounting students who were not involved in either context of the educational process. This comparison group represents the average student who has not been trained to focus on a particular aspect of an accounting or ethics case.

The ANOVA omnibus F-statistic indicates an overall difference between groups, yet post hoc analysis shows that the difference is between the comparison group and the accounting context group. The comparison group reasoned at a higher level than the other two (trained) groups; however, it should be noted that the comparison group mean was not statistically significant from the ethics context group. Although we cannot explain this anomaly, prior accounting ethics research has reported that the average college student possesses a higher level of ethical reasoning than accounting majors (Armstrong, 1987, and Lampe and Finn, 1992). One explanation is that the framework of accounting education may foster a lower (pre-conditional) level of moral reasoning. In the current study, the ethics and accounting context groups received training that may have increased their accounting-specific orientation, which, in turn, may have reduced their level of moral reasoning.

Our primary interest is in impact of the accounting and ethics contexts within the delivery of the educational process. Therefore, we have omitted the comparison group from further analysis and compare the ethical context group ( $\mathrm{n}=61)$ to the accounting context group $(\mathrm{n}=50)$. As shown in Table 4 , the results indicate a significant difference between the means, with the ethical context group exhibiting a higher level of moral reasoning $($ mean $=$ $3.41)$ than the accounting context group (mean $=2.90, \mathrm{p}=0.048)$. Work experience remains significant $(\mathrm{p}=0.012)$. 
Table 4: Means and ANOVA Results for Additional Analysis

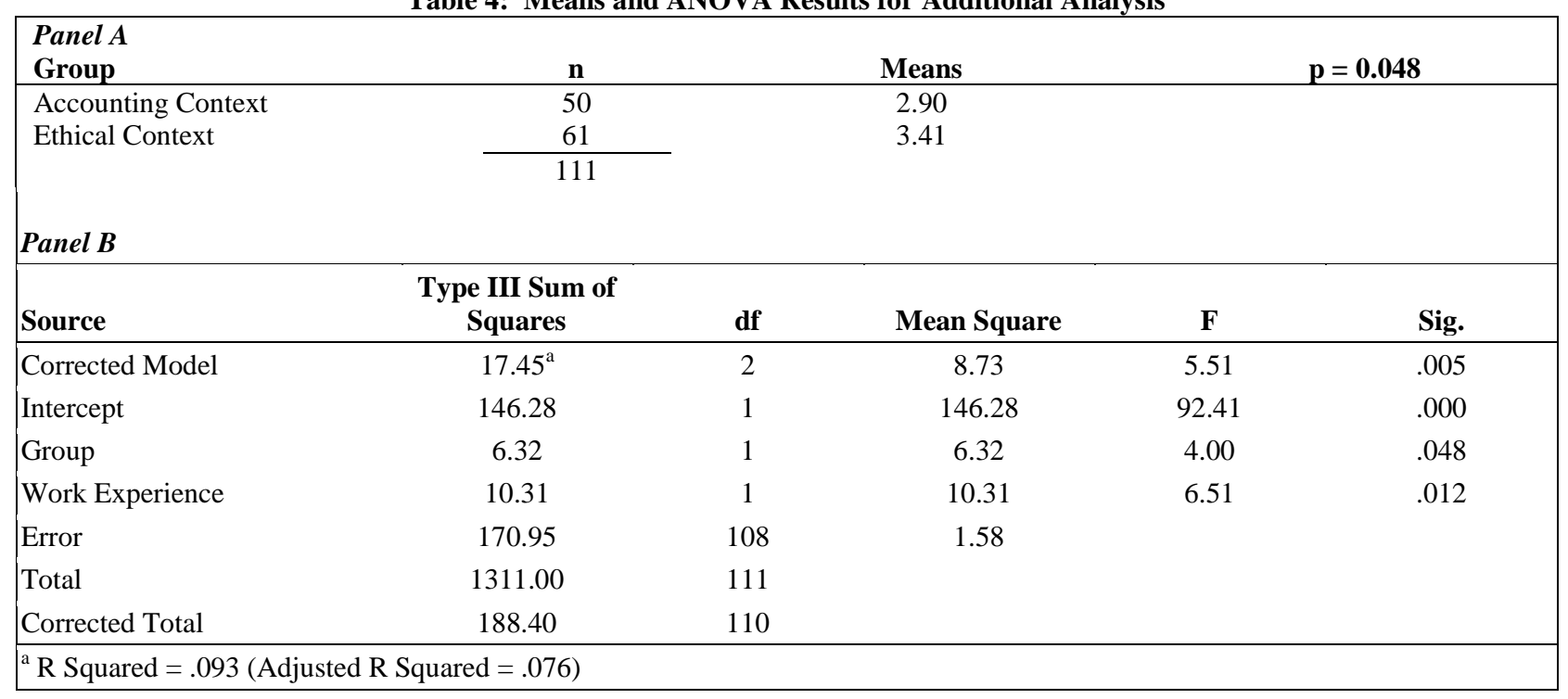

\section{DISCUSSION}

The study of accounting ethics education is a complex subject, resulting in a number of different approaches to the delivery and measurement of ethics education. Our intent was to document whether the context (ethical or accounting) in which an educational process was delivered would have measurable effects on ethical sensitivity and levels of moral reasoning. In this research, we found that placing the student in an ethical context improved measures of ethical sensitivity and moral reasoning. The contributions of the current study are the measurements of the effect of educational context on: 1) ethical sensitivity in a setting that does not provide obvious ethical implications and 2) the level of moral reasoning.

\section{LIMITATIONS}

We recognize that this preliminary study includes limitations that should be addressed in future research. For example, Shadish, Cook, and Campbell (2002) argue for a pretest to determine whether a treatment is effective. To avoid alerting the students to the (un)ethical nature of the scenario, we elected to forego a pretest and instead relied on a comparison group to determine the effectiveness of the educational process. The unexpected results for the second research question may be specific to our sample; future replications may provide further insight.

The study was conducted over multiple semesters and students were not randomly assigned to conditions. Although the final educational process was consistently applied at the same university by the same instructor, it is possible that there may have been unknown underlying differences between semesters. We encourage other educators to replicate the study at multiple universities where the educational process is delivered by more than one instructor.

\section{FUTURE RESEARCH}

Each educational process was administered over a single semester. Future studies could extend this research to multiple semesters or throughout the academic career of accounting students to determine if accounting ethics education prepares students to make sound ethical judgments.

Fleming et al. (2009) suggest that “...traditional audit-based emphasis on ethics in accounting curricula may be inadequate for developing accounting students with ethical decision-making competencies required by the diverse segments of the accounting profession" (pg. 14). Thus, we question, "Will a comprehensive educational 
process introduced early in the accounting curriculum contribute to the development of ethical sensitivity and moral reasoning of accounting students?" We anticipate that additional research on the topic will help provide answers.

\section{AUTHOR INFORMATION}

Mary Jo Billiot, CPA, is an Associate Professor of Accounting at New Mexico State University. Her primary teaching responsibilities are Cost and Governmental/Not-for-Profit accounting. Her research interests include the teaching and learning topics. E-mail: mbilliot@nmsu.edu

David Daniel is an Associate Professor of Applied Statistics at New Mexico State University, where he teaches undergraduate and graduate courses in statistics and statistical software, and helps oversee an MS program in Applied Statistics. He also serves as a general consulting statistician within the university, does private consulting, and has worked in R\&D in industry. E-mail: ddaniel@ nmsu.edu

Sid Glandon, CPA, CFP ${ }^{\circledast}$, is an Associate Professor and Interim Chair of the Department of Accounting at the University of Texas at El Paso. He has published articles in Issues in Accounting Education and Review of Business Information Systems. His research interests include business ethics and ethics education. E-mail: sglandon@utep.edu

TerryAnn Glandon, CPA, is an Associate Professor of Accounting at the University of Texas at El Paso. She teaches courses in technology and undergraduate and graduate accounting systems. She has published articles in the Journal of Accountancy, Review of Business Information Systems and Internal Auditing. E-mail: tglandon@utep.edu. Corresponding author.

\section{REFERENCES}

1. Abdolmohammadi, M. 2005. Ethical training in graduate accounting courses: effects of intervention and gender on students' ethical reasoning. Research on Professional Responsibility and Ethics in Accounting 10:37-62.

2. Armstrong, M. B. 1987. Moral development and accounting education. Journal of Accounting Education Spring:27-43.

3. Armstrong, M. B., J. E. Ketz, and D. Owsen. 2003. Ethics education in accounting: moving toward ethical motivation and ethical behavior. Journal of Accounting Education 21:1-16.

4. Cohen, J. R., L. W. Pant, and D. J. Sharp. 2001. An examination of differences in ethical decision-making between Canadian business students and accounting professionals. Journal of Business Ethics 30:319-336.

5. Coyne, M., D. Massey, and J. Thibodeau. 2005. Raising students' ethical sensitivity with a value relevance approach. Advances in Accounting Education:Teaching and Curriculum Innovations 7.

6. Delaney, J., and M. J. Coe. 2008. Does ethics instruction make a difference? Advances in Accounting Education:Teaching and Curriculum Innovations 9:233-250.

7. Douglas, P. C., and B. N. Schwartz. 1998. A longitudinal study of the effect of teaching ethics throughout the accounting curriculum. Research on Accounting Ethics 4:89-112.

8. Earley, C. E., and P. T. Kelly. 2004. A Note on Ethics Educational Interventions in an Undergraduate Auditing Course: Is There an "Enron Effect"? Issues in Accounting Education 19 (1):53-71.

9. Fleming, D. M., R. N. Romanus, and S. M. Lightner. 2009. The Effect of Professional Context on Accounting Students' Moral Reasoning. Issues in Accounting Education 24 (1):13-30.

10. Fulmer, W. E., and B. R. Cargile. 1987. Ethical Perceptions of Accounting Students: Does Exposure to a Code of Professional Ethics Help? Issues in Accounting Education 2 (2):207.

11. Green, S., and J. Weber. 1997. Influencing ethical development: exposing students to the AICPA code of conduct. Journal of Business Ethics 16:777-790.

12. Huss, H. F., and D. M. Patterson. 1993. Ethics in Accounting: Values Education Without Indoctrination. Journal of Business Ethics 12 (3):235-243.

13. Kohlberg, L. 1981. The philosophy of moral development : moral stages and the idea of justice. 1st ed. San Francisco: Harper \& Row.

14. Langenderfer, H. Q., and J. W. Rockness. 1989. Integrating Ethics into the Accounting Curriculum: Issues, Problems, and Solutions. Issues in Accounting Education 4 (Spring):58-69. 
15. Massey, D. W., and L. Thorne. 2006. The Impact of Task Information Feedback on Ethical Reasoning. Behavioral Research in Accounting 18:103-116.

16. Mintz, S. 2007. Loeb's contribution to accounting ethics education and research. Research on Professional Responsibility and Ethics in Accounting 11:31-46.

17. Patterson, D. M. 2001. Causal effects of regulatory, organizational and personal factors on ethical sensitivity. Journal of Business Ethics 30:123-159.

18. Rest, J. R. 1979. Development in judging moral issues. Minneapolis: University of Minnesota Press.

$19 . \quad$ 1986. Moral Development: Advances in Research and Theory. New York: Praeger.

20. 1994. Moral development in the professions: psychology and applied ethics Hillsdale, NJ: L. Erlbaum.

21. Shadish, W. R., T. D. Cook, and D. T. Campbell. 2002. Experimental and Quasi-Experimental Designs for Generalized Causal Inference Houghton Mifflin Company.

22. Shaub, M. K., D. W. Finn, and P. Munter. 1993. The effects of auditors' ethical orientation on commitment and ethical sensitivity. Behavioral Research in Accounting 5:145-169.

23. Welton, R. E., R. M. Lagrone, and J. R. Davis. 1994. Promoting the moral development of accounting graduate students: an instructional design and assessment. Accounting Education 3 (1):35.

24. Wright, G. B., C. P. Cullinan, and D. M. Bline. 1998. Recognizing ethical issues: the joint influence of ethical sensitivity and moral intensity. Research on Accounting Ethics 4:29-52. 